\title{
Generation Model of Optimal Emergency Treatment Technology for Sudden Heavy Metal Pollution Based on Group-G1 Method
}

\author{
Liu Ying ${ }^{1 *}$, Du Qianying ${ }^{2}$, Cheng Zhihui ${ }^{1}$, Chen Junwen ${ }^{1}$, Lin Zhengjiang ${ }^{1}$ \\ ${ }^{1}$ Faculty of Geosciences and Environmental Engineering, Southwest Jiaotong University, Chengdu, China \\ ${ }^{2}$ Sichuan Huadi Environmental Science and Technology Co. Ltd, Chengdu, China
}

Received: 5 February 2021

Accepted: 3 May 2021

\begin{abstract}
Heavy metals have the characteristics of high toxicity, refractory and easy enrichment, so it is necessary to quickly choose the best emergency treatment technology to deal with them after the sudden heavy metal pollution. To select and evaluate the emergency treatment technology of heavy metals, the evaluation index system of emergency treatment technology of sudden heavy metal pollution was established by selecting nine indexes from three aspects of emergency technical characteristics, emergency treatment cost and social environmental impact. The Group-G1 method based on DempsterShafer evidence theory was studied to establish the optimal emergency treatment technology generation model, the weight of evaluation indexes was obtained from the expert weight and G1 weight. And then the TOPSIS method was used to comprehensively evaluate the selected emergency treatment technology. Finally, the cadmium pollution incident in Longjiang River, Guangxi Province, China in 2012 was taken as an example to verify the feasibility of the model. The results show that the generation model can quickly and accurately screen out the best emergency treatment technology for sudden heavy metal pollution.
\end{abstract}

Keywords: emergency treatment technology, Dempster-Shafer evidence theory, group-G1, heavy metal pollution

\section{Introduction}

Recently, the rapid development of industry has brought huge economic benefits. Heavy metals are important industrial raw materials, and heavy metal industry has the characteristics of high energy

*e-mail: 642823770@qq.com consumption and heavy pollution. Therefore, waste residue and wastewater generated in heavy metal industrial production activities lead to frequent heavy metal pollution accidents $[1,2]$. Heavy metal pollution is different from other organic compounds pollution, and it is difficult for heavy metals to be degraded by selfpurification of water. Moreover, heavy metals are easy to accumulate in organisms. It enters the human body through the food chain and eventually accumulates in some organs, causing chronic and acute poisoning 
and endangering human health [3, 4]. Therefore, after the sudden heavy metal pollution, it is particularly important to quickly screen the best emergency treatment technology for promoting emergency work. The heavy metal water pollution accidents are often uncertain, sudden and extremely harmful, leading to the emergency process has certain passiveness and complexity. So that it is difficult to obtain a scientific and efficient emergency treatment technology scheme in time when the accident occurs.

Recently, studies on the screening and evaluation approaches of emergency treatment technology for sudden water pollution accidents have started. Liu, et al. [5] established a historical case database of oilspilling accidents at sea, and realized the automatic retrieval and matching of oil emergency treatment technology by utilizing the overall similarity algorithm of target accident. Qu, et al. [6] extracted historical case technologies to construct the emergency disposal case database of water source sudden pollution, and realized the optimization of emergency disposal technology in combination with the threat analysis approach. Liu, et al. [7] established the historical case database of sudden pollution accidents, matched the target accident with historical cases, and then obtained the optimal emergency treatment technology of the target accident by using the multi-attribute decision-making method. The existing studies start with a historical case database, and determine the optimum emergency treatment technology by calculating the similarity between the target accident and historical cases. However, for some heavy metal water pollution accidents that occur infrequently, there are few historical cases that can be referenced, which conspicuously limit the updating of technology in the case database. Moreover, for some relatively remote cases, the rationality of the technology adopted at that time deserves serious consideration. In addition, with the continuous emergence of new technologies, it is worth verifying whether the emergency technology used in historical cases is optimum. In brief, the emergency technologies that can only be provided by historical cases are limited. Therefore, this study has combined historical cases and water pollution treatment engineering examples to establish a heavy metal pollution treatment technology database (https:// doi.org/10.6084/m9.figshare.13701097.v1), including 26 River Basin pollution events and 70 engineering cases (Information system of chemical pollution accident in River Basin, National Copyright Administration of the People's Republic of China, 2020SR0103598). The technology database not only makes full use of the valuable experience of historical cases, but also avoids its limitations. Moreover, the application of emergency treatment technology was introduced into the evaluation index system, and the technology maturity and project implementation were taken into account in the comprehensive evaluation process of emergency technology.
At present, the studies on screening and evaluation methods of emergency treatment technology at home and abroad mainly focus on the use of analytic hierarchy process (AHP) [8-11], improved analytic hierarchy process (IAHP) $[6,12,13]$, the entropy weight method $[7,14,15]$ and other methods to calculate the weight of the indexes of emergency treatment technology evaluation system, and then evaluate emergency treatment technology. However, AHP has nine grades, which makes it difficult to pass the consistency test. IAHP only needs three-grade scales, but judgment matrix, the transfer matrix and quasi-uniformity matrix need to be calculated. When there are many indexes, the calculation amount is large. The entropy weight method is an objective-weighting method, but objective data are usually difficult to obtain. In addition, selection and evaluation of emergency treatment technology is a group decision-making process of many experts. The above methods do not reflect the impact of expert weight on the index weight, which makes the final obtained index weight more subjective, and has a certain impact on the credibility and accuracy of the evaluation results. Dempster-Shafer (D-S) evidence theory [16, 17] is widely used in medical diagnosis, engineering applications and expert systems [18]. This theory can make use of the knowledge and experience of experts to make decisions when the information base is incomplete and eliminate the conflict of opinions among experts. Therefore, this study used D-S evidence theory to calculate the distance between the standardized values of the index importance ranking ordinal number of each expert, and then obtained the expert weight. The G1 method [19] can accurately show the importance of each index, and does not need consistency test, so it has the advantage of simple calculation. Therefore, this study used Group-G1 method based on D-S evidence theory to determine the index weight of the evaluation system through G1 weight and expert weight, which effectively reduced the subjectivity of index weight; the TOPSIS method was used to evaluate the emergency treatment technology comprehensively, and the optimal emergency treatment technology was screened out.

\section{Methods}

\section{Evaluation Index of Emergency Treatment Technology}

\section{Determination of the Index System}

In the heavy metal pollution treatment technology database, the indexes were initially selected: water environment characteristics (water discharge, $\mathrm{pH}$ range, temperature); technical characteristics (application, removal efficiency, removal rate, range of treatable concentrations, reliance on engineering (which refers to whether there are water conservancy facilities such as bridges, gate dams or ditches in the polluted area of 
the drainage basin), difficulty of project implementation, difficulty in accessing emergency material, stability of emergency materials); economic costs (manpower costs, material costs, transportation costs, waste disposal costs); social environmental impact (water environmental quality, environmental impact of waste, environmental impact of residues, impact to social economic activities, public acceptability). After an indepth analysis of the indexes, it was found that some indexes are related to each other, such as mutual penetration and interference. Therefore, through consulting with several experts, 14 indexes were finally determined to achieve the optimization of emergency treatment technology.

Five indexes (water discharge, $\mathrm{pH}$ range, temperature, range of treatable concentrations and reliance on engineering), can be objectively measured by accident scene monitoring data as primary identification indexes. Considering the independence, comprehensiveness and operability of the indexes, nine secondary evaluation indexes were determined from the perspectives of technical characteristics, economic costs, and social environmental impact. The secondary evaluation index system of emergency treatment technology is constructed as shown in Fig. 1, which is composed of the target layer, the criterion layer, the index layer, and the scheme layer.

The primary identification indexes were adopted to preliminarily identify the alternative technologies in the emergency treatment technology database, and then the secondary evaluation indexes in Fig. 1 were used to evaluate and sort the alternative technologies. Finally, the technology with the highest score was selected as the optimal emergency treatment technology for the accident.

\section{Establishment of Scoring Criteria for Indexes}

To make quantitative and qualitative indexes had relatively objective and reasonable scoring criteria, each
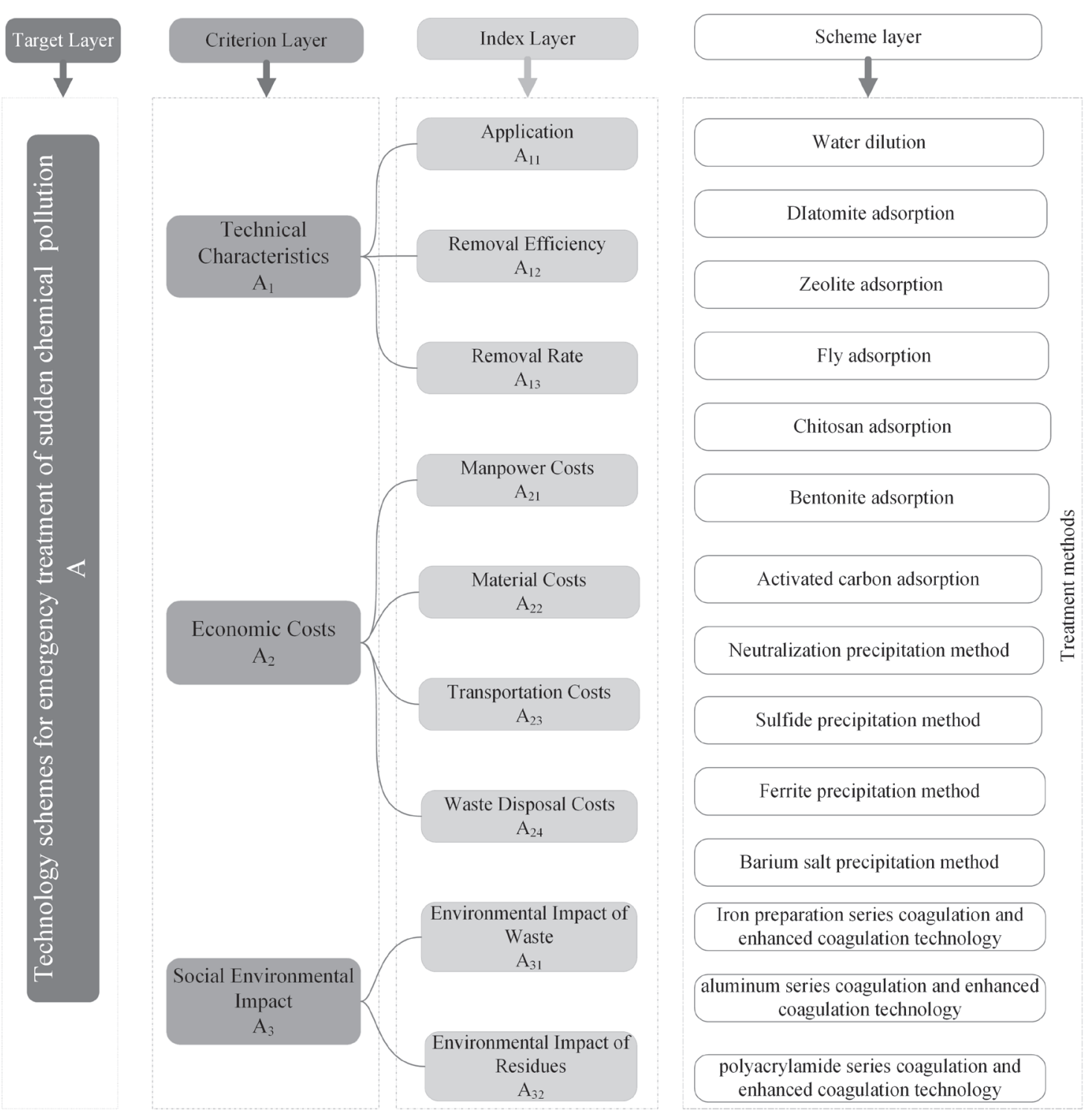

Fig. 1. Evaluation index system of emergency treatment technology for sudden heavy metal pollution. 
level score of criteria was given in the form of interval. The scoring criteria of evaluation indexes are shown in Table 1. After the accident of heavy metal pollution, the emergency treatment experts gave the score of each index according to the score criteria.

\section{Emergency Treatment Technology Generation Model}

\section{Primary Selection of Emergency Treatment Technology}

After heavy metal pollution accident happened, according to the basic information indexes of receiving waterbody in Table 2, the appropriate emergency treatment technology was first selected from sudden heavy metal pollution emergency treatment technology database. The applicability of emergency treatment technology is affected by four water environment characteristic indexes (water temperature, flow rate, $\mathrm{pH}$ value range, pollutants concentrations). For example, when oxidizing organic pollutants by Fenton reagent, $\mathrm{pH}$ should be less than 7; when adsorb organic pollutants in water by using steel slag with particle size of 120-180 mesh, the water temperature should be greater than $15^{\circ} \mathrm{C}$. Some technology's realization, such as water diversion and dilution, need water conservancy projects, which require the presence of lakes and reservoirs upstream to provide diluted water. And these five indexes can be objectively measured by the accident site monitoring data, which can simply and quickly remove the obvious unsuitable technology from the technology database.

Then the Group-G1 method based on D-S evidence theory and TOPSIS method was used to evaluate primary selected emergency treatment technologies, and finally the best emergency treatment technology was obtained.

Table 1. Scoring criteria for evaluation indexes.

\begin{tabular}{|c|c|c|}
\hline Index & Scoring criteria & $\begin{array}{l}\text { Score } \\
\text { interval }\end{array}$ \\
\hline \multirow{3}{*}{$\begin{array}{c}\text { Application } \\
\left(\mathrm{A}_{11}\right)\end{array}$} & I: the technology is in maturity stage and has been applied widely & {$[7,10]$} \\
\hline & II: the technology is in maturity stage and has been applied less & {$[4,6]$} \\
\hline & III: the technology is in research stage and have no practical application & {$[0,3]$} \\
\hline \multirow{3}{*}{$\begin{array}{l}\text { Removal } \\
\text { efficiency } \\
\qquad\left(A_{12}\right)\end{array}$} & I: $80 \% \leq \eta$ & {$[7,10]$} \\
\hline & II: $50 \% \leq \eta<80 \%$ & {$[4,6]$} \\
\hline & III: $\eta<50 \%$ & {$[0,3]$} \\
\hline \multirow{3}{*}{$\begin{array}{c}\text { Removal rate } \\
\left(\mathrm{A}_{13}\right)\end{array}$} & $\mathrm{I}: \mathrm{T} \leq 12 \mathrm{~h}$ & {$[7,10]$} \\
\hline & II: $12 \mathrm{~h}<\mathrm{T} \leq 24 \mathrm{~h}$ & {$[4,6]$} \\
\hline & III: $\mathrm{T}>24 \mathrm{~h}$ & {$[0,3]$} \\
\hline \multirow{3}{*}{$\begin{array}{l}\text { Manpower } \\
\text { costs } \\
\left(\mathrm{A}_{21}\right)\end{array}$} & I: the implementation of the technology has high manpower costs & {$[7,10]$} \\
\hline & II: the implementation of the technology has moderate manpower costs & {$[4,6]$} \\
\hline & III: the implementation of the technology has low manpower costs & {$[0,3]$} \\
\hline \multirow{3}{*}{$\begin{array}{c}\text { Material costs } \\
\left(\mathrm{A}_{22}\right)\end{array}$} & I: the implementation of the technology has high material costs & {$[7,10]$} \\
\hline & II: the implementation of the technology has moderate material costs & {$[4,6]$} \\
\hline & III: the implementation of the technology has low material costs & {$[0,3]$} \\
\hline \multirow{3}{*}{$\begin{array}{c}\text { Transporta- } \\
\text { tion costs } \\
\left(\mathrm{A}_{23}\right)\end{array}$} & I the implementation of the technology has high transportation costs & {$[7,10]$} \\
\hline & II: the implementation of the technology has moderate transportation costs & {$[4,6]$} \\
\hline & III: the implementation of the technology has low transportation costs & {$[0,3]$} \\
\hline \multirow{3}{*}{$\begin{array}{l}\text { Waste dis- } \\
\text { posal costs } \\
\left(\mathrm{A}_{24}\right)\end{array}$} & I: the implementation of the technology has high waste disposal costs & {$[7,10]$} \\
\hline & II: the implementation of the technology has moderate waste disposal costs & {$[4,6]$} \\
\hline & III: the implementation of the technology has low waste disposal costs & {$[0,3]$} \\
\hline \multirow{3}{*}{$\begin{array}{c}\text { Environmen- } \\
\text { tal impact of } \\
\text { waste } \\
\left(\mathrm{A}_{31}\right)\end{array}$} & I: the waste substance after the implementation of the technology has greater impact on the environment. & {$[7,10]$} \\
\hline & II: the waste substance after the implementation of the technology has some impact on the environment. & {$[4,6]$} \\
\hline & III: the waste substance after the implementation of the technology has a less impact on the environment. & {$[0,3]$} \\
\hline \multirow{3}{*}{$\begin{array}{l}\text { Environmen- } \\
\text { tal impact of } \\
\text { residues } \\
\left(\mathrm{A}_{32}\right) \\
\end{array}$} & I: the residual substance after the implementation of the technology has greater impact on the environment. & {$[7,10]$} \\
\hline & II: the residual substance after the implementation of the technology has some impact on the environment. & {$[4,6]$} \\
\hline & III: the residual substance after the implementation of the technology has a less impact on the environment. & {$[0,3]$} \\
\hline
\end{tabular}


Table 2. Meaning description of water environment characteristics indexes.

\begin{tabular}{|c|c|}
\hline Index & Meaning description \\
\hline Water discharge & $\begin{array}{l}\text { The size of the water flow in the polluted area of river basin for which the emergency treatment } \\
\text { technology is applicable }\end{array}$ \\
\hline $\mathrm{pH}$ range & $\begin{array}{c}\text { The } \mathrm{pH} \text { range of the water in the polluted area of river basin for which the emergency treatment } \\
\text { technology is applicable }\end{array}$ \\
\hline Temperature & $\begin{array}{l}\text { The temperature of the water body in the polluted area of river basin for which the emergency } \\
\text { treatment technology is applicable }\end{array}$ \\
\hline Range of treatable concentrations & The concentration range of pollutants that can be removed by emergency treatment technology \\
\hline Reliance on engineering & $\begin{array}{l}\text { Whether there are Bridges, DAMS and sluices, rivers and ditches, lakes and reservoirs in the } \\
\text { polluted area that can be used for emergency treatment technology. }\end{array}$ \\
\hline
\end{tabular}

\section{Group-G1 Method Based on D-S Evidence Theory}

G1 method is a subjective weighting method, which improves the shortcomings of AHP and has the advantages of simple calculation and no need of consistency test [15]. G1 method sorts the importance degree of evaluation indexes by experts, and assigns the importance ratio of two adjacent evaluation indexes to get the G1 weight value of evaluation indexes. The specific process of G1 weighting of a single expert is as follows:

(1) Suppose a total of $q$ experts are invited to give G1 weight to the evaluation indexes, then the $s$-th $(s=1,2, \ldots, q)$ expert compares the indexes $x_{1}, \ldots, x_{j}$, $\ldots, x_{n}(j=1,2, \ldots, n)$ of each level in Fig. 1 according to the importance degree. Finally, the indexes at each level are sorted in descending order, denoted as $x_{1}^{(s) *}>\ldots>x_{j}^{(s)^{*}} \ldots>x_{n}^{(s)^{*}}$, where $x_{j}^{(s)^{*}}$ represents the $j$-th index after the $s$-th expert ranks the evaluation indexes according to the importance degree.

(2) After determining the order between the indexes, the $s$-th expert assigns a value to the importance degree ratio $r_{n}^{(s)}$ of two adjacent indexes $x_{k-1}^{(s)^{*}}$ and $x_{k}^{(s)^{*}}(k=n$, $n-1, \ldots, 2)$, the assignment criteria are shown in Table 3.

(3) According to the value of $r_{n}^{(s)}$, calculating the G1 weight value $w_{k}^{(s)^{*}}$ of the $s$-th expert to the index $x_{n}^{(s)^{*}}$ through formula (1).

$$
w_{n}^{(s) *}=\left(1+\sum_{l=2}^{n} \prod_{k=l}^{n} r_{k}^{(s)}\right)^{-1}
$$

4) Then, the G1 weight value of the $s$-th expert to the other indexes is obtained using the following formula:

$$
w_{k-1}^{(s) *}=r_{k}^{(s)} w_{k}^{(s) *}
$$

(5) The weights $w_{j}^{(s)}$ of each index before ranking are obtained from the G1 weight values $w_{n}^{(s)}$ and $w_{k-1}{ }^{(s)^{*}}$, where $w_{j}^{(s)}$ represents the G1 weight value of the $s$-th expert to the index $x_{i}$.

Then, obtain the expert weight, $w_{j}^{(s)}$, through calculating the distance between the standardized values of the index importance ranking ordinal number of each expert on D-S evidence method.

Assume that $\Pi$ is the set of indexes at each level in Fig. 1, and its non-empty subset is the index $x_{p}(p=1,2, \ldots, j, \ldots, f, \ldots, n)$. The standardized values of the importance ranking ordinal number of the indexes $\left(x_{1}, \ldots, x_{j}, \ldots, x_{n}\right)$ by each expert are taken as the basic trust assignment functions and denoted as $m_{y}(y=1,2$, $\ldots, s, \ldots, t, \ldots, q)$, then the distance, $d_{s t}$, of any two sets of basic trust assignment functions can be obtained from formulas (3)-(6) [18, 20].

$$
\begin{gathered}
d_{s t}=\sqrt{\frac{1}{2}\left\|m_{s}\right\|^{2}+\left\|m_{t}\right\|^{2}-2\left\langle m_{s}, m_{t}\right\rangle} \\
\left\|m_{s}\right\|^{2}=\left\langle m_{s}, m_{s}\right\rangle \\
\left\|m_{t}\right\|^{2}=\left\langle m_{t}, m_{t}\right\rangle \\
\left\langle m_{s}, m_{t}\right\rangle=\sum_{j=1}^{n} \sum_{f=1}^{n} m_{s}\left(x_{j}\right) m_{t}\left(x_{f}\right) \frac{\left|x_{j} \cap x_{f}\right|}{\left|x_{j} \cup x_{f}\right|}
\end{gathered}
$$

In the formulation, $\left|x_{j} \cap x_{f}\right|$ represents that $x_{j} \cap x_{f}$ contains the number of non-empty subsets of set $\Pi$; $\left|x_{j} \cup x_{f}\right|$ indicates that $x_{j} \cup x_{f}$ contains the number of non-empty subsets of set $\Pi ; m_{s}\left(x_{j}\right)$ represents the standardized value of the importance ranking ordinal number of the $j$-th evaluation index by the $s$-th expert; $m_{t}\left(x_{f}\right)$ represents the standardized value of the

Table 3. $r_{n}^{(s)}$ assignment criteria.

\begin{tabular}{|c|c|}
\hline$r_{n}^{(s)}$ & Definition \\
\hline 1.0 & $x_{k-1}^{(s) *}$ is as important as $x_{k}^{(s) *}$. \\
\hline 1.2 & $x_{k-1}^{(s)^{*}}$ is slightly more important than $x_{k}^{(s)^{*}}$. \\
\hline 1.4 & $x_{k-1}^{(s)^{*}}$ is significantly more important than $x_{k}^{(s)^{*}}$. \\
\hline 1.6 & $x_{k-1}^{(s)^{*}}$ is strongly more important than $x_{k}^{(s)^{*}}$. \\
\hline 1.8 & $x_{k-1}^{(s)^{*}}$ is extremely important than $x_{k}^{(s)^{*}}$. \\
\hline
\end{tabular}


importance ranking ordinal number of the $t$-th expert for the $f$-th evaluation index.

According to formulas (3)-(6), $d_{\text {st }} \in[0,1]$. The value of $d_{s t}$ is smaller, the distance between the two groups of basic trust assignment functions is smaller, indicating that the two experts are more unified in ranking the importance of evaluation indexes; in contrast, the value of $d_{s t}$ is larger, the distance between the two groups of basic trust assignment functions is greater, which means the greater the difference between the two experts in ranking the importance of evaluation indexes.

Suppose a total of $q$ experts are invited to rank the importance of the evaluation indexes, and the distance matrix $D_{q \times q}$ is obtained by calculating the formula (7).

$$
D=\left[\begin{array}{cccccc}
0 & d_{12} & \cdots & d_{1 t} & \cdots & d_{1 q} \\
\vdots & \vdots & & \vdots & & \vdots \\
d_{s 1} & d_{s 2} & & d_{s t} & \cdots & d_{s q} \\
\vdots & \vdots & & \vdots & & \vdots \\
d_{q 1} & d_{q 2} & \cdots & d_{q t} & \cdots & 0
\end{array}\right]
$$

Then the total support degree $\beta\left(m_{s}\right)$ that the basic trust assignment function $m_{s}$ is supported by other basic trust assignment functions can be expressed by the following formula:

$$
\beta\left(m_{s}\right)=\sum_{t=1, t \neq s}^{q}\left(1-d_{s t}\right)
$$

According to the value of $\beta\left(m_{s}\right)$, the weight value $(\theta)$ of the $s$-th expert can be calculated using the following formula:

$$
\theta_{s}=\frac{\beta\left(m_{s}\right)}{\sum_{s=1}^{q} \beta\left(m_{s}\right)}
$$

In the formulation, $0<\theta_{s}<1$, and $\Sigma_{\mathrm{s}=1}^{\mathrm{q}} \theta_{s}=1$. The value of $\theta_{s}$ is higher, the weight of experts is higher, and the greater the proportion of G1 weight given by experts in the index weight; in contrast, the proportion of G1 weight value given by experts in the index weight is smaller.

The weight of each evaluation index is jointly determined by the expert weight value and G1 weight value. The weight value of the evaluation index is larger, the evaluation index is more important, and the proportion of index score is larger in the evaluation of emergency treatment technology; otherwise, the proportion of index score is smaller. The weight $W_{j}$ of index $x_{j}$ is calculated as follows:

$$
W_{j}=\sum_{s=1}^{q} \theta_{s} w_{j}^{(s)}
$$

\section{Evaluation of Emergency Treatment Technology Based on TOPSIS Method}

In this study, the TOPSIS method was used to evaluate the emergency treatment technology. This method can use the relative closeness to objectively reflect the similarity between the emergency treatment technology and the optimal solution, intuitively reflect the gap between the technologies and select the appropriate emergency treatment technology for heavy metal pollution accident. First, the experts score each secondary index of emergency treatment technology according to Table 1, and the maximum and minimum values of each index score value constitute the optimal solution and the worst solution, respectively. Then, the distance between the emergency treatment technique and the optimal solutions or the worst solution is calculated, and the relative closeness between the emergency treatment technique and the optimal solution is obtained. Finally, the relative closeness of each emergency treatment technology is arranged in the order of large to small, and the emergency treatment technology with the largest relative closeness is the best.

The detailed calculation process of TOPSIS method is as follows:

(1) Assuming that there are a total of emergency treatment technologies initially selected and $n$ secondary indexes, the experts score the secondary indexes of the $i$-th emergency treatment technology according to the scoring criteria (Table 1). The score value is expressed as $u_{i}=\left[u_{i 1}, u_{i 2}, \ldots, u_{i n}\right]$, where $i=1,2$, ..., e. The decision matrix $U$ constructed from the score values can be expressed as

$$
U=\left[\begin{array}{c}
u_{1} \\
u_{2} \\
\vdots \\
u_{e}
\end{array}\right]=\left[\begin{array}{cccc}
u_{11} & u_{12} & \cdots & u_{1 n} \\
u_{21} & u_{22} & \cdots & u_{2 n} \\
\vdots & \vdots & & \vdots \\
u_{e 1} & u_{e 2} & \cdots & u_{e n}
\end{array}\right]_{e \times n}
$$

(2) The normalized decision matrix $V=\left[v_{i j}\right]$ is obtained by normalizing the elements in the decision matrix $U$ according to the formula (12).

$$
v_{i j}=\frac{u_{i j}}{\sqrt{\sum_{i=1}^{e} u_{i j}^{2}}}
$$

(3) The maximum and minimum values of each column in the normalized decision matrix $V$ are taken as the optimal solution $v^{+}$and the worst solution $v^{-}$ respectively, as shown in formulas (13)-(14).

$$
\begin{aligned}
& v^{+}=\left\{v_{1}^{+}, \cdots, v_{j}^{+}, \cdots, v_{n}^{+}\right\} \\
& v^{-}=\left\{v_{1}^{-}, \cdots, v_{j}^{-}, \cdots, v_{n}^{-}\right\}
\end{aligned}
$$

In the formulation, $v_{j}^{+}=\max \left\{v_{1 j}, v_{2 j}, v_{3 j}, \ldots, v_{e j}\right\} ; v_{j}^{-}=$ $\max \left\{v_{1 j}, v_{2 j}, v_{3 j}, \ldots, v_{e j}\right\}$, where $j=1,2, \ldots, n$. 
(4) From the optimal solution $v^{+}$and the worst solution $v^{-}$, the distance $Y_{i}^{+}$between emergency treatment technology and the optimal solution, and the distance $Y_{i}^{-}$between emergency treatment technology and the worst solutions are calculated respectively. The distance formula is as follows:

$$
\begin{gathered}
Y_{i}^{+}=\sqrt{\sum_{j=1}^{n}\left[W_{j}^{*}\left(v_{i_{j}}-v_{j}^{+}\right)\right]^{2}} \\
Y_{i}^{-}=\sqrt{\sum_{j=1}^{n}\left[W_{j}^{*}\left(v_{i_{j}}-v_{j}^{-}\right)\right]^{2}}
\end{gathered}
$$

...where $W_{j}^{*}$ represents the global weight, and its value is the product of the weight of the $j$-th column secondary index and the weight of the primary index.

(5) According to the value of $Y_{i}^{+}$and $Y_{i}^{-}$, the relative closeness $H_{i}$ between emergency treatment technology and the optimal solution is calculated by the following formula:

$$
H_{i}=\frac{Y_{i}^{-}}{Y_{i}^{-}+Y_{i}^{+}}
$$

The relative closeness of each emergency treatment technology is ranked from large to small, and the value of $H_{i}$ is larger, the emergency treatment technology is more suitable for this sudden heavy metal pollution; in contrast, the treatment effect of the emergency treatment technology for this sudden heavy metal pollution is worse.

\section{Application Steps of Emergency Treatment Technology Generation Model}

The optimal emergency treatment technology generation model proposed in this paper aims to quickly screen out the most suitable emergency treatment technology after the sudden heavy metal pollution in the basin, reduce the time spent in selecting treatment technology, and achieve the purpose of improving the efficiency of emergency treatment. The technical steps of the model-screening emergency handling are shown in Fig. 2.

\section{Discussion}

\section{Case Analysis}

In this study, Longjiang River cadmium accident in Guangxi Province, China, was taken as an example to verify the generation model of optimal emergency treatment technology.

On January 17, 2012, the highest cadmium concentration at $200 \mathrm{~m}$ in front of the dam of Lalang

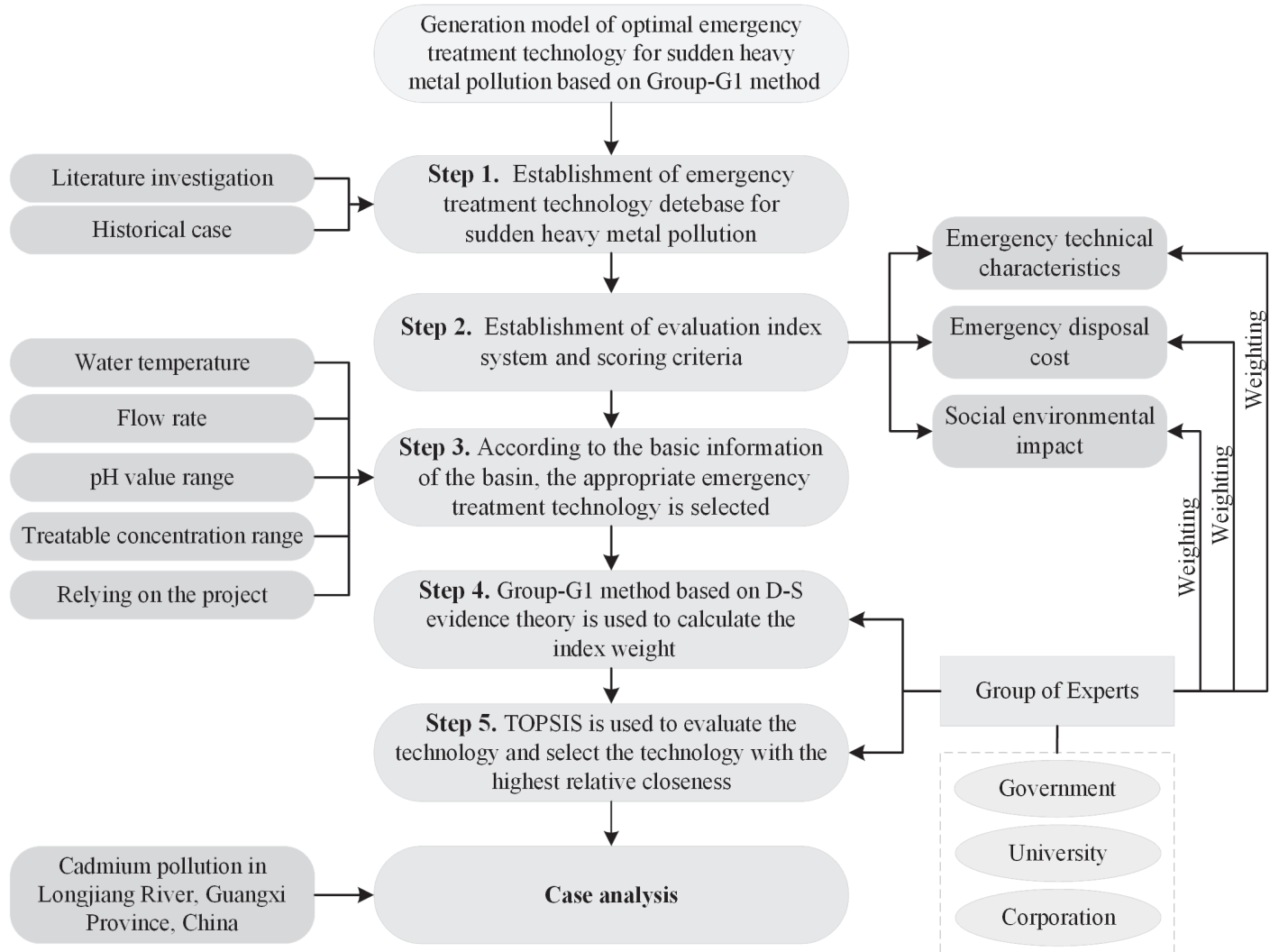

Fig. 2. Application steps of generating model of optimal emergency treatment technology. 


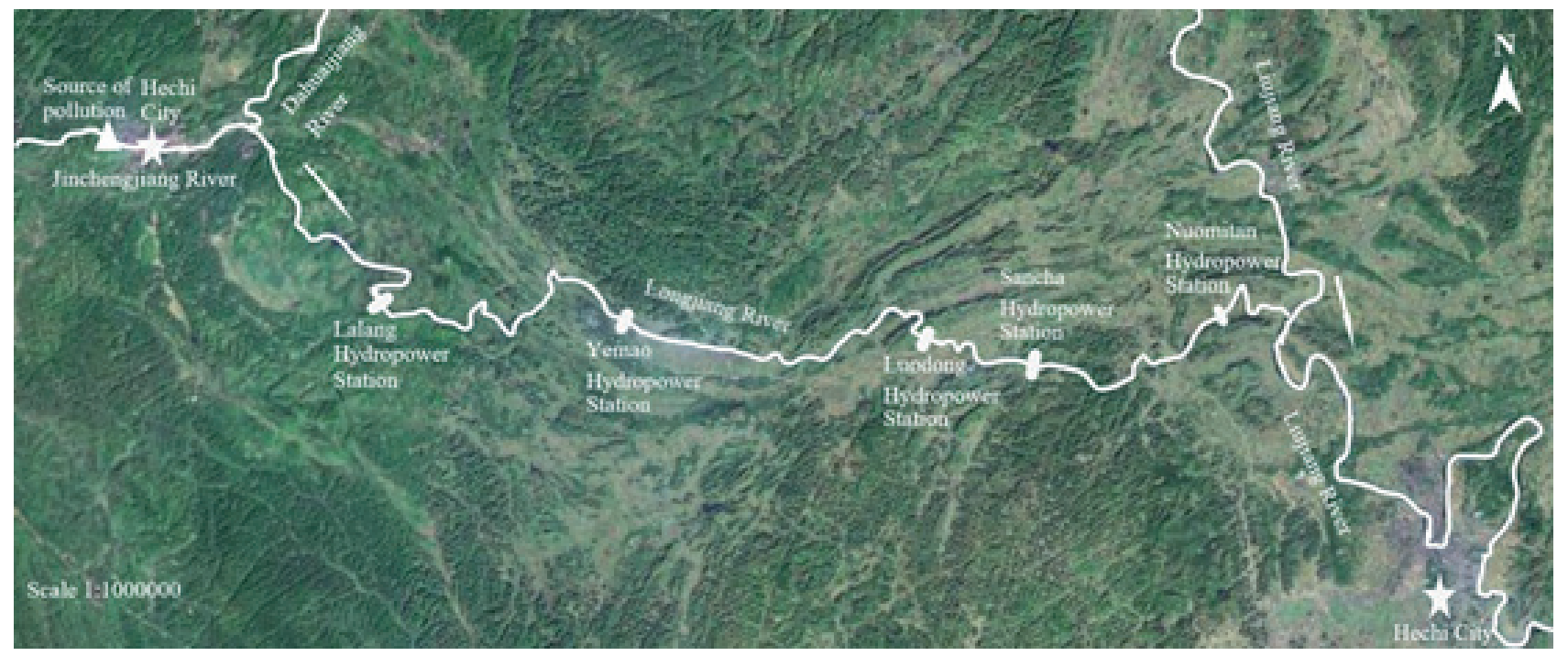

Fig. 3. The location map of cadmium pollution accident.

Hydropower Station in Longjiang River reached $0.408 \mathrm{mg} / \mathrm{L}$, which was 81.6 times higher than standard limit of Class III water body in the Environmental Quality Standard for Surface Water. The length of the pollution group was $25 \mathrm{~km}$, and the downstream was the Liujiang River section of Liuzhou drinking water source protection [21]. The relevant location of cadmium pollution accident is shown in Fig. 3.

After the investigation, the water temperature of Longjiang River was about $10^{\circ} \mathrm{C}$, the average flow was about $147 \mathrm{~m}^{3} / \mathrm{s}$, the $\mathrm{pH}$ value was 7.6 7.8. Yemao Hydropower Station, Luodong Hydropower Station, Sancha Hydropower Station and Nuomitan Hydropower Station were in the lower reaches. According to the above information, four suitable emergency treatment technologies had been successfully selected from the established emergency technology database of sudden heavy metal cadmium: diatomite adsorption technology, polyaluminium ferric silicate coagulation technology, enhanced polyaluminium chloride coagulation technology and enhanced ferric chloride coagulation technology.

Ten environmental protection experts in emergency treatment were invited to assign the importance degree of evaluation indexes according to the local economic and geographical conditions, and calculated the weight of indexes by formulas (1)-(10). The calculation results are shown in Table 4.

According to the scoring criteria (Table 1), the emergency treatment experts scored the four selected emergency treatment technologies, and then combined the weight of evaluation indexes (Table 4) to calculate the relative closeness of the four emergency treatment technologies by using formulas (11)-(17). The results are shown in Table 5. It can be seen from Table 5 that the emergency treatment technology with the greatest relative closeness is enhanced polyaluminum chloride coagulation technology, which is the best emergency treatment technology screened out by the generation model in this paper. In the experiment and

Table 4. Weights of evaluation indexes.

\begin{tabular}{|c|c|c|c|c|}
\hline Primary Index & $\begin{array}{c}\text { Index } \\
\text { weight }\end{array}$ & Secondary Index & $\begin{array}{c}\text { Index } \\
\text { weight }\end{array}$ & $\begin{array}{l}\text { Global } \\
\text { weight }\end{array}$ \\
\hline \multirow{3}{*}{ Emergency technical characteristics $\mathrm{B}_{1}$} & \multirow{3}{*}{0.4577} & Removal velocity $\mathrm{C}_{1}$ & 0.3339 & 0.1528 \\
\hline & & Removal rate $\mathrm{C}_{2}$ & 0.2827 & 0.1212 \\
\hline & & Application situation $\mathrm{C}_{3}$ & 0.4015 & 0.1838 \\
\hline \multirow{4}{*}{ Emergency disposal cost $\mathrm{B}_{2}$} & \multirow{4}{*}{0.2630} & Material cost $\mathrm{C}_{4}$ & 0.2728 & 0.0718 \\
\hline & & Waste disposal cost $\mathrm{C}_{5}$ & 0.2981 & 0.0784 \\
\hline & & Labor $\operatorname{cost} \mathrm{C}_{6}$ & 0.2306 & 0.0606 \\
\hline & & Transportation $\operatorname{cost} \mathrm{C}_{7}$ & 0.1986 & 0.0522 \\
\hline \multirow{2}{*}{ Social environmental impact $\mathrm{B}_{3}$} & \multirow{2}{*}{0.2793} & Environmental impact of residues $\mathrm{C}_{8}$ & 0.5403 & 0.1509 \\
\hline & & Environmental impact of waste $\mathrm{C}_{9}$ & 0.4597 & 0.1284 \\
\hline
\end{tabular}


Table 5. Relative closeness and optimization order of emergency treatment technology.

\begin{tabular}{|c|c|c|}
\hline Order & Technology & Relative closeness \\
\hline No. 1 & Enhanced polyaluminium chloride coagulation technology & 0.6683 \\
\hline No. 2 & Polyaluminium ferric silicate coagulation technology & 0.4267 \\
\hline No. 3 & Enhanced ferric chloride coagulation technology & 0.3591 \\
\hline No. 4 & Diatomite adsorption technology & 0.3364 \\
\hline
\end{tabular}

practical application, sodium hydroxide and calcium hydroxide are often used to enhance the removal effect of coagulant. In the application operation, the type of intensifier can be determined according to the actual emergency material reserve.

After the cadmium pollution accident in Longjiang River on January 17, 2012, the expert group on January 24 determined that the emergency treatment technology for cadmium pollution in Longjiang River was sodium hydroxide enhanced polyaluminium chloride coagulation technology. Four power stations were set up as the treatment points. At the entrance of the power station, the $\mathrm{pH}$ value of the river water was increased to $8.1-8.4$ by adding sodium hydroxide. At the exit of the power station, polyaluminium chloride was added to make the cadmium in the water form precipitation and eventually sink to the river bottom by the strong mixing effect of the power plant, to achieve the purpose of reducing cadmium. On February 21, the water quality of the polluted river reached the standard [22, 23]. It can be seen that the technology selected by the optimal emergency response technology generation model proposed in this study is consistent with the technology used in the actual case, which proves the feasibility of the model.

\section{Conclusions}

The dynamic optimization system constructed in this paper provides an efficient approach for discriminating the optimal emergency treatment technology for sudden chemical accidents. On the basis of considering the basic applicable conditions of technology, the primary identification indexes were determined and the alternative technologies were identified in the technology database. Then, the hierarchical structure of the secondary evaluation indexes was established by combining the technical characteristics, economic costs, and social environmental impact. According to the information in the secondary evaluation indexes of actual cases, comprehensive evaluation and sorting of alternative technologies were realized. Finally, the feasibility of the optimal emergency treatment technology generation model was validated by Longjiang River cadmium accident in Guangxi Province, China.

The results suggested that the optimization system has significant feasibility. (a) The emergency treatment technology database was established combining historical cases and water pollution treatmentengineering examples, which not only makes full use of the valuable experience of historical cases, but also avoids its limitations as far as possible. (b) The Group-G1 method based on D-S evidence theory was put forward, which used D-S evidence theory to calculate the weight of experts, so that the weight of evaluation indexes integrated the knowledge and experience of many experts, comprehensively considered the influence of experts on the index weight, and eliminated the opinion conflict among experts. (c) The TOPSIS method was used to evaluate the emergency treatment technology comprehensively. And the relative closeness was used to reflect the similarity between the emergency treatment technology and the optimal solution objectively, intuitively reflected the gap between the various technologies intuitively, to select emergency treatment technologies suitable for sudden heavy metal pollution accidents. (d) The dynamic optimization system established in this study can quickly identify the optimal emergency treatment technology in line with the accident within one hour after the detailed investigation of the accident scene by experts, greatly shortening the emergency response time. It can provide feasible reference for the implementation of emergency response engineering for pollutant elimination.

\section{Acknowledgements}

This study was supported by the National Natural Science Foundation of China (No. 51779211 and No. 51209178), and the Science and Technology Project of Sichuan Province (No.2019YJ0233).

\section{Conflict of Interest}

The authors declare no conflict of interest.

\section{References}

1. HE J. Study on the present situation and treatment methods of heavy metal pollution in water body in China. China Metal Bull, No. 991, (04), 241+243, 2018. 
2. LIU J., HUANG Y., XIAO W. Identification and Disposal of Common Pollutants in Sudden Environmental Events. South China University of Technology Press: Guangzhou, China, 2017

3. CHEN Q. Study on the harm of environmental heavy metal pollution and environmental restoration. Environment And Development, (8), 52, 54, 2018.

4. KOU W., ZHAO W., ZHANG J. Analysis of Typical Cases of Environmental Pollution Accidents and Countermeasures for Environmental Emergency Management. China Environmental Science Press: Beijing China, 2013.

5. LIU J., ZHU F., ZHANG Y., YANG X. A marine oilspilling emergency auxiliary decision-making system based on case-based reasoning. A marine oil-spilling emergency auxiliary decision-making system based on case-based reasoning, 2013

6. QU J., MENG X., YOU H. Evaluation system for emergency disposal technology insurface drinking water source pollution. Journal of Harbin Institute of Technology, 47, (8), 54, 2015.

7. LIU R., GUO L., JIANG J., LIU J., WANG P. A CBRMADM based two-step screening model of emergency disposal technology for chemical spills. China Environmental Science, 35 (3), 943, 2015.

8. GINER-SANTONJA G., CALVO V.V., LEPE, G.R. Application of AHP and corrective factors for the determination of best available techniques and emission limit values at installation level: A case study in four cement installations. The Science of the Total Environment, 660 (APR.10), 834, 2019.

9. KHOSHAND A., KAMALAN H., REZAEI H. Application of analytical hierarchy process (AHP) to assess options of energy recovery from municipal solid waste: a case study in Tehran, Iran. Journal of Material Cycles \& Waste Management, 20 (3), 1, 2018

10. QU J. Study on the Emergency Decision-Making Support System Based on the Evaluation and Selection of Emergency Treatments of Water Source Pollutions. Harbin Institute of Technology, Harbin, China, 2014.

11. ZHANG Z. Study on the Screening and Assessment System of The Emergency Treatments of Sudden Chemical
Pollution. Harbin Institute of Technology, Harbin, China 2013.

12. BAO J., ZHANG J., SHI S., JAN J., SRIKANTA P. Cleaner production assessment of group company based on improved AHP and grey relational analysis. Journal of Intelligent and Fuzzy Systems, 35 (1), 1, 2018.

13. MIAO Z., SONG W., ZHEN C., JI W. Risk assessment for fire and explosion accidents of steel oil tanks using improved AHP based on FTA. Process Safety Progress, 35, 2016.

14. KOSEOGLU B., BUBER M., TOZ A.C. Optimum site selection for oil spill response center in the Marmara Sea using the AHP-TOPSIS method. Archives of Environmental Protection, 44 (4), 2018.

15. WANG S., LV R., LI D., LIU Z. Fuzzy comprehensive evaluation of flight support equipment maintenance contractor based on Entropy Weight and G1 method. Ordnance Industry Automation, (12), 52-55, 59, 2016.

16. SHAFER G. A Mathematical Theory of Evidence. Princeton University Press: Princeton, 1976.

17. YANG F., WANG X., Conflict Evidence Combination Method Based on D-S Evidence Theory. National Defense Industry Press: Beijing, China, 2010.

18. GUO Y., Theory and method of comprehensive evaluation. Science Press: Beijing, 2002.

19. XUEJUN W., YAJUN G. Analyzing the Consistency of Comparison Matrix Based on G1 Method. Chinese Journal of Management Science, 14 (3), 2006.

20. JOUSSELME A.L., GRENIER D., BOSSÉ É. A new distance between two bodies of evidence. Information Fusion, 2 (2), 91, 2001.

21. ZHANG X., CHEN C., MI Z., WANG C. Emergent cadmium removal technology for drinking water and measures for environmental accident in Guangxi Longjianghe river. Water \& Wastewater Engineering, 000 (001), 24, 2013.

22. LIU W. Study on the Technology of Pollution Isolation and Treatment of Drinking Water Source in Longjiang River. Hunan Agricultural University, Changsha,China, 2013.

23. PROTECTION., M.O.E. Cadmium Pollution Emergency Treatment Technology. China Environment Press: Beijing,China, 2015. 